\title{
Foot pathology in insulin dependent diabetes
}

\author{
S J Barnett, J P H Shield, M J Potter, J D Baum
}

\begin{abstract}
Objectives-Foot pathology is a major source of morbidity in adults with diabetes. The aim of this study was to determine if children with insulin dependent diabetes have an increased incidence of foot pathology compared with non-diabetic children. Design-Questionnaire, clinical examination, and biomechanical assessment.

Subjects-67 diabetic children and a comparison group matched for age, sex, and social class.

Results-We found significantly more foot pathology in the children with diabetes (52 children) than the comparison group (28 children); with more biomechanical anomalies ( 58 children with diabetes, 34 comparison group); and a higher incidence of abnormal skin conditions (53 children with diabetes, 27 comparison group). Forty two children with diabetes had received foot health education compared with 27 in the comparison group, but the study revealed ignorance and misconceptions among the diabetic group, and previous contact with a podiatrist was minimal.

Conclusions-The survey suggests that children with diabetes have an increased incidence of foot pathology justifying greater input of podiatric care in the hope of preventing later problems.

(Arch Dis Child 1995; 73: 151-153)
\end{abstract}

Keywords: insulin dependent diabetes mellitus, foot pathology, podiatry.

It is generally acknowledged that a large proportion of foot ulcers due to diabetes are preventable. ${ }^{1}$ Ulceration can affect the patient's entire life and can lead to morbidity, hospitalisation, and in some cases amputation. ${ }^{2}$ Many papers have been published concerning the feet of adults with diabetes, linking pressure overload to ulceration, ${ }^{3-7}$ and advocating the prevention of foot ulceration. ${ }^{89}$ Consequently it is now widely accepted that the podiatrist is an important member of the diabetes care team in adult practice. ${ }^{1011}$ Santopietro has stated the importance of biomechanical analysis and treatment in paediatrics, ${ }^{12}$ and Gramuglia et al has discussed the importance of biomechanical concepts in the treatment of ulcers in the diabetic foot. ${ }^{13}$ However, there have been few studies on the treatment of biomechanical foot anomalies in the diabetic child with a view to preventing later onset ulceration.

Subjects and methods

A total of 67 insulin dependent diabetic children took part in the study, of whom 36 were female and 31 were male. The median age was 13 years (range 5-18 years). They came from all social groups, with a mean duration of diabetes of 4.9 years (range $<1-15$ years) and were recruited from the two paediatric diabetic outpatient clinics at Bristol Royal Hospital for Sick Children. Consent to take part in the study was obtained from the children or their parents/guardians. A comparison group of 67 non-diabetic children was obtained from schools in the Bristol area and each child was matched to a child with diabetes for age, sex, and social class.

The principal researcher (SJB) collected data using an interview/examination questionnaire, based on the recommendations of Kippen. ${ }^{14}$ Footwear was examined, followed by gait analysis, biomechanical assessment, and recording of pathology. Foot health opinions were sought at the end of the questionnaire. Personal details, medical history, including duration of diabetes, and social class were recorded.

Footwear was examined using a combination of criteria recommended by Bamford, ${ }^{15}$ and the Wessex feet report. ${ }^{16}$ Abnormal wear on the shoe was recorded to aid the biomechanical assessment. Controls were examined using the same protocol as the diabetic group. The examiner was aware that these children did not have diabetes. Children with any medical condition were excluded from the comparison group.

We used visual gait assessment to attempt to identify major abnormalities of the trunk and limb, and biomechanical assessment to examine the range of motion available in the foot and lower limb using guidelines and normal values described by Root et al. ${ }^{17}$ The examination was performed as suggested by Sgarlato, ${ }^{18}$ in conjunction with simple manipulation and standard techniques to judge whether measurement was necessary, as validated by Kilmartin and Wallace. ${ }^{19}$ Because the subjects were children, ranges of motion were considered normal if they were in the correct ratio, rather than using rigid parameters for degrees of motion which are appropriate only for adults.

We compiled a list of foot abnormalities for example, hallux valgus, callus, onychocryptosis, hallux limitus, as suggested by Larsen et $a l,{ }^{20}$ and assessed them using the criteria of the Wessex feet report. ${ }^{16} \mathrm{We}$ noted also if tinea pedis and verruca pedis were present.

We included posterior tuberosity or heel bumps as these are common in young females ${ }^{21}$ and are exacerbated by footwear. We took as the criteria for diagnosis detection of a firm, fibro-fatty swelling over the posterior aspect of the calcaneus. We recorded any foot 
Table 1 Incidence of skin conditions in children with diabetes and comparison group; figures are number (\%)

\begin{tabular}{lccc}
\hline & $\begin{array}{l}\text { Diabetic } \\
\text { children } \\
(n=67)\end{array}$ & $\begin{array}{l}\text { Comparison } \\
\text { group } \\
(n=67)\end{array}$ & $\begin{array}{c}\text { Significance } \\
(\text { p value) }\end{array}$ \\
\hline Excessively dry & $3(4)$ & $1(1)$ & $\mathrm{NS}$ \\
Excessively humid & $30(45)$ & $7(10)$ & $<0 \cdot 001$ \\
Lesions (for example bullae, fissures, and cuts) & $32(48)$ & $14(21)$ & $<0 \cdot 01$ \\
Inflammation & $1(1)$ & $3(4)$ & $\mathrm{NS}$ \\
Haematoma & $12(18)$ & $6(9)$ & $\mathrm{NS}$ \\
Total No of subjects with one or more abnormality & $52(78)$ & $27(40)$ & $<0 \cdot 001$ \\
\hline
\end{tabular}

injury and any history of trauma or repeated sprain or strain. Nail care was examined and assessed as described in the Wessex feet report. ${ }^{16}$

We assessed joint mobility using the children's hands, recording if they were unable to appose their palms completely. ${ }^{22}$ This was assessed to enable comparison between limited mobility in the hand and the feet.

Where appropriate, analysis of the data for statistical purposes was performed using the $\chi^{2}$ distribution test, chosen because the majority of data existed in the form of cross tabulation of the frequencies. Where applicable we used McNemar's test for matched pairs.

\section{Results}

Some questions offered the subject more than one answer. For completeness all answers were recorded, so some figures total more than 67 $(100 \%)$.

Shoe length was adequate in $35(52 \%)$ of the subjects with diabetes compared with 54 $(81 \%)$ of the comparison group $(p<0.001)$. Skin abnormalities (hyperhidrosis, anhidrosis, infections, bullae), were detected in 52 (78\%) of the children with diabetes (comparison group $27(40 \%) ; p<0.001)$. These were particularly common in diabetic females $(92 \%)$ compared with female controls $(56 \% ; \mathrm{p}<0.001)$. Hyperhidrosis was seen most commonly in diabetic males, while cutaneous lesions (bullae, cuts, fissures) were more common in the females with diabetes (see table 1). Biomechanical anomalies were found in 58 $(87 \%)$ of the subjects with diabetes and 34 $(51 \%)$ of the comparison group $(p<0.001$; see table 2). Fifty two (78\%) of the children with diabetes had evidence of foot pathology (comparison group $28(42 \%) ; \mathrm{p}<0.001$; see table 3).

Table 2 Biomechanical anomalies in children with diabetes and comparison group; figures are number (\%)

\begin{tabular}{lccl}
\hline & $\begin{array}{c}\text { Diabetic } \\
\text { children } \\
(n=67)\end{array}$ & $\begin{array}{l}\text { Comparison } \\
\text { group } \\
(n=67)\end{array}$ & $\begin{array}{l}\text { Significance } \\
(p \text { value })\end{array}$ \\
\hline Juvenile pes planovalgus & $5(7)$ & $1(1)$ & $0 \cdot 1$ \\
Pes cavus & $3(4)$ & $2(3)$ & NS \\
Hindfoot (calcaneo) varus & $29(43)$ & $9(13)$ & $0 \cdot 01$ \\
Forefoot varus (supinated) & $2(3)$ & $1(1)$ & NS \\
Metatarus primus varus & $4(6)$ & $6(9)$ & NS \\
Digital deformaties & $25(37)$ & $11(16)$ & $0 \cdot 01$ \\
Hypermobility & $30(45)$ & $14(21)$ & $0 \cdot 01$ \\
Genu varum & $1(1)$ & 0 & NS \\
Genu valgum & $1(1)$ & $2(3)$ & NS \\
Tibial torsion & $6(9)$ & $2(3)$ & NS \\
Limb length discrepancy & $2(3)$ & 0 & NS \\
Hyperextended first interphalangeal joint & $2(3)$ & 0 & NS \\
Total No of subjects with one or more biomechanical & & & \\
$\quad$ anomaly & $58(87)$ & $34(51)$ & $0 \cdot 001$ \\
\hline
\end{tabular}

Limited range of mobility in the hands was detected in $22 \%$ of the subjects with diabetes (comparison group $15 \%, \mathrm{p}<0.05$ ). In every case toe deformity was also present, but there was no limitation of subtalar movement. In $33 \%$ of the children with diabetes the toe nails had been cut in an acceptable manner (comparison group $67 \% ; \mathrm{p}<0.001)$. Forty two $(63 \%)$ of the children with diabetes had received some form of foot health education compared with $27(40 \%)$ of the non-diabetic children; $55(82 \%)$ of them felt that their condition made foot care important.

\section{Discussion}

In 1980, Larsen et al found that children with diabetes had more foot pathology than other children, ${ }^{20}$ recommending along with others ${ }^{2324}$ an extensive foot health education programme.

Fifteen years later we have found that footwear is still less adequate in diabetic subjects than a control group, primarily because the shoes were too short: Marr and D'Abrera recorded similar findings in 1985.25 Skin abnormalities were more common in the children with diabetes. The increased incidence of tinea pedis in boys with diabetes, and increased prevalence of verrucae in girls with diabetes may be related to the increased incidence of hyperhidrosis recorded, but may also suggest that diabetes increases susceptibility to cutaneous infections. Callus was more common in children with diabetes. It is possible that this is related to the much higher incidence of biomechanical anomalies providing areas of overload in the feet. ${ }^{12627}$ This factor may also be responsible for the higher incidence of damage, mainly bullae, in the diabetic group. However, the higher incidence of inadequate footwear and the tendency for diabetic skin to blister more readily ${ }^{28-30}$ could also be responsible for this phenomenon.

We frequently observed rearfoot pathologies and hypermobility. This contributed to the high incidence of ankle sprains, and also the high percentage of hallux limitus, although undoubtedly habitually wearing footwear that was too short may have exacerbated this condition. ${ }^{25}$ Hallux limitus, often combined with hyperextended first interphalangeal joints, is a recognised ulceration site in adults with diabetes, ${ }^{831}$ so is an abnormality which should be given priority consideration for orthotic control and footwear advice.

Table 3 The pathologies present in children with diabetes and comparison group; figures are number (\%)

\begin{tabular}{lccc}
\hline & $\begin{array}{c}\text { Diabetic } \\
\text { children } \\
(n=67)\end{array}$ & $\begin{array}{l}\text { Comparison } \\
\text { group } \\
(n=67)\end{array}$ & $\begin{array}{l}\text { Significance } \\
\text { ( } p \text { value })\end{array}$ \\
\hline Onychocryptosis & $10(15)$ & $4(6)$ & $<0.1$ \\
Hallux limitus & $44(66)$ & $23(34)$ & $<0.001$ \\
Heel bump & $34(51)$ & $20(30)$ & $<0.05$ \\
Callus & $53(79)$ & $20(30)$ & $<0.001$ \\
Verruca & $13(19)$ & $10(15)$ & NS \\
$\begin{array}{l}\text { Tinea pedis } \\
\text { Hallux valgus }\end{array}$ & $12(18)$ & $4(6)$ & $<0.05$ \\
Total No of subjects & $3(4)$ & $2(3)$ & NS \\
$\quad$ & & & \\
$\quad \begin{array}{llll}\text { with one or more foot } \\
\text { pathology }\end{array}$ & $52(78)$ & $28(42)$ & $<0.001$ \\
\hline
\end{tabular}


Hallux valgus was present only in girls, indicating that it may have been exacerbated by inadequate footwear ${ }^{32}$ as well as foot type. Children with a foot type prone to developing hallux valgus would benefit from podiatric treatment and advice to prevent a potential ulcer site when adult. ${ }^{32} 33$ Posterior tuberosities (heel bumps) were more common in girls with diabetes. This might be explained by the fact that, as a group, they appeared to have the least adequate footwear. This deformity can lead to ulceration in adults with diabetes and is a site notorious for difficulty in healing. A better approach would be prevention in the young patient by conservative treatment and advice. ${ }^{34}$

Every child who displayed limited joint mobility in the hands also showed digital deformity in the feet. However, no limitation of subtalar motion was found, unlike that in a study of adults with diabetes by Delbridge et $a .^{4}$ Our patients may have been too young to exhibit limited subtalar motion, but studying limited joint mobility in the hands and digital deformities in the feet could give an early warning of impaired foot mobility. In adults with diabetes this predisposes to ulceration in susceptible neuropathic feet. ${ }^{3-7}$

We were disappointed that while the level of foot health education received by those with diabetes was higher than controls, their foot health practice, such as shoe fit, was worse. The small number of children who had been in contact with a podiatrist is a cause for concern. We recommend closer links between paediatricians and podiatrists to deal with this problem. ${ }^{35} \mathrm{It}$ is, however, encouraging that so many children with diabetes believed foot care important, ${ }^{23}$ although the fact that almost half of them did not know why indicates the need for further foot health education.

Children with diabetes are at greater risk of developing foot pathology than non-diabetic children, ${ }^{20}$ and they have a need for more foot health education ${ }^{23}$ and regular podiatric assessment to recognise and treat pathology in its early stages.

1 Brand PW. The diabetic foot. In: Ellenburg M, Rifkin H, eds. Diabetes mellitus: theory and practice. 3rd Ed. New York: Medical Examination Publishing Company, 1983: 827-49.

2 Masson EA, Angle S, Roseman P, Wilson I, Coton M, Boulton AJM. Diabetic foot ulcers - do patients know 22-3.

3 Roy KJ. Force, pressure, and motion measurements in the foot: current concepts. Clin Podiatr Med Surg 1988; 5: 491-508.

4 Delbridge L, Perry P, Marr S, et al. Limited joint mobility in the diabetic foot: relationship to neuropathic ulceration. Diabet Med 1988; 5: 333-7.

5 Brand PW. Repetitive stress in the development of diabetic foot ulcers. In: Levin ME, O'Neale LW, eds. The diabetic foot. 4th Ed. St Louis: CV Mosby, 1988: 83-90

6 Fernando DJS, Masson EA, Veves A, Boulton AJM Relationship of limited joint mobility to abnormal foot pressures and diabetic ulceration. Diabetes Care 1991; 14: 8-11.

7 Young RJ. Identification of the subject at risk of foot ulceration. In: Conner H, Boulton AJM, Ward JD, eds. The foot in diabetes. Chichester: John Wiley and Sons, 1987: 23-31.

8 Boulton AJM. The diabetic foot. Med Clin North Am 1988; 72: 1513-30.

9 Duffy JC, Patout CA. Management of the insensitive foot in diabetes: lessons learned from Hansen's disease. Mil Med diabetes: lessons lear

10 Tovey F. Care of the diabetic foot. Practical Diabetes 1986; 3: $130-4$.

11 Burden AC, Samanta A, Jones R. Setting up an advanced foot clinic in a district general hospital. Practical Diabetes 1986; 3: 262 .

12 Santopietro FJ. Foot and foot related injuries in the young athlete. Clin Sports Med 1988; 7: 563-89.

13 Gramuglia VJ, Palmarozzo PM, Rzonca EC. Biomechanical concepts in the treatment of ulcers in the diabetic foot. Clin Podiatr Med Surg 1988; 5: 613-26.

14 Kippen C. Foot health education - an observational analysis. The Chiropodist 1988; 43: 57-60.

15 Bamford VJ. A study of foot health education needs at Belstead special school. The Chiropodist 1986; 41: 294-312.

16 Brodie BS, Rees CL, Robins DJ, Wilson AFJ. Wessex feet: a regional foot health survey. The Chiropodist 1988; 43: 152-65.

17 Root ML, Orien WP, Weed JH, Hughes RJ. Biomechanical evaluation of the foot. Los Angeles: Clinical Biomechanics Corporation, 1971; 1: 34-131.

18 Sgarlato TE. A compendium of podiatric biomechanics. San Francisco: California College of Podiatric Medicine, 1971: 78-108.

19 Kilmartin TE, Wallace WA. Podiatric screening for abnormalities predisposing to juvenile foot deformity. The Chiropodist 1990; 45: 205-6.

20 Larsen K, Katz L, Nielsen B. Footwear and deformities in diabetic childrens feet. The Chiropodist 1980; 11: 435-7.

21 Neale D. Common foot disorders - diagnosis and management. 2nd Ed. Edinburgh: Churchill Livingstone, 1985: 55-62.

22 Brice JEH, Johnston D, Noronha JL. Limited finger joint mobility in diabetes. Arch Dis Child 1982; 57: 879-81.

23 Rosenquist U, Carlson A, Luft R. Evaluation of a comprehensive programme for diabetes care at primary healthhensive programme for diabetes care at priate

24 Court S, Sein E, McCowen C, Hackett A F, Park NJM. Children with diabetes mellitus: perception of their behavioural problems by parents and teachers. Early Hum Dev 1988; 16: 45-52.

25 Marr SJ, D'Abrera HJM. Survey of joint mobility and foot problems of 191 Australian children. $\mathcal{f} \mathrm{Am}$ Podiatr $\mathrm{Med}$ Assoc 1985; 75: 597-602.

26 Young MJ, Cavanagh PR, Thomas G, Johnson MM, Murrey $\mathrm{H}$, Boulton AJM. The effect of callus removal on dynamic plantar foot pressures in diabetic patients. Diabet Med 1992; 9: 55-7.

27 Cavanagh PR, Ulbrecht JS. Biomechanics of the diabetic foot: a quantitative approach to the assessment of neuropathy, deformity and plantar pressure. In: Jahss $\mathrm{MH}$, ed. Disorders of the foot. 2nd Ed. Philadelphia: WB ed. Disorders of the foot.
Saunders, 1991: 1864-907.

28 Toonstra J. Bullosis diabeticorum. F Am Acad Dermatol 1985; 13: 799-805.

29 Cantwell AR, Martz W. Idiopathic bullae in diabetics. Arch Dermatol 1967; 96: 42-4.

30 Allen GE, Hadden DR. Bullous lesions of the skin in diabetes (bullosis diabeticorum). Br $\mathcal{F}$ Dermatol 1970: 82: 216-20.

31 Cavanagh PR, Sanders LJ, Sims DS. The role of pressure distribution measurement in diabetic foot care. Rehabilitation $R$ EO $D$ Progress Reports 1987; 25: 53-4.

32 Delbridge L, Ctercteko G, Fowler C, Reeve TS, Le Quesne LP. The aetiology of diabetic neuropathic foot ulceration. Br f Surg 1985; 72: 1-6.

33 Sage R. A fine design for foot care. Diabetes Forecast 1991; 11: $72-5$.

34 Ahroni JH. Teaching foot care creatively and successfully. The Diabetes Educator 1993; 19: 320-6.

35 Edmonds ME. Experience in a multidisciplinary diabetic foot clinic. In: Conner H, Boulton AJM, Ward JD, eds. The foot in diabetes. Chichester: John Wiley and Sons, 1987: 121-33. 